\title{
Mudanca social e teoria da economia solidária. Uma perspectiva maussiana
}

\section{JEAN-LOUIS LAULLE"}

\section{Resumo}

Neste artigo, o autor analisa, à luz da teoria da dádiva, a evolução das instituições da economia social, confrontando as concepções que orientavam sua criação às constatações empíricas de seu funcionamento. Constatando, com Mauss, não haver um modo único de organização da economia que expresse uma ordem natural, mas sim diferentes formas de produção e de repartição que coexistem, conclui que, passar a um projeto democrático de mudança social implica levantar a questão das instituições em condições de assegurar a pluralidade da economia para inscrevê-la em um quadro democrático.

Palavras chave: Economia social. Associativismo. Sociologia econômica. Dádiva.

Social change and the theory of solidarity economy. A Maussian approach $^{1}$

\section{Abstract}

In this article, the author examines, in the light of the theory of the gift, the development of social economy institutions, contrasting their early conceptions

\footnotetext{
Conservatoire National des Arts et Métiers, CNAM- Paris (França)

1 Tradução de Patrícia C.R. Reuillard (UFRGS). Revisão de Antonio David Cattani (UFRGS).
} 
and their observed operation. Following Mauss, he notes that there is no single mode of economic organization that expresses a natural order, but rather different forms of production and distribution that coexist. Thus, in order to accomplish a democratic project of social change, it is necessary to raise the question of what institutions are able to ensure the diversity of the economy so that to inscribe it within a democratic framework.

Keywords: Social economy. Collective initiatives. Economic sociology. The gift.

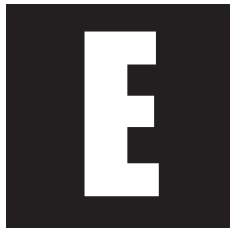

m um período em que a dominação capitalista acarreta um aumento inédito das desigualdades sociais e um preocupante desequilíbrio ambiental, a questão de uma mudança social como vetor de democratização adquire especial relevância.

Ao resgatar as concepções que marcaram o século XX, vou mostrar como essas se revelaram problemáticas quando confrontadas com as constatações empíricas. A partir de meu próprio percurso de pesquisa, assinalo o quanto os dados extraídos da observação puseram em questão as ideias nessa área.

Primeiramente, a crença de que o controle do Estado poderia transformar o modo de produção foi afetada pela trajetória dos países comunistas: o exemplo da lugoslávia busca mostrar que nem mesmo seu modelo dissidente, baseado na autogestão, permitiu um avanço notável.

Essa distância - entre os objetivos visados e os resultados atingidos por essa perspectiva macrossocial - evidencia outra acepção da mudança, que passa mais por experiências microssociais. É a tradição da economia social, precursora de entidades coletivas, sejam elas associativas, cooperativas ou mutualistas, que pode então ser examinada. Seu aporte também se revela decepcionante, já que a contribuição dessas entidades ficou reduzida por um isomorfismo institucional que as aproximou das empresas privadas capitalistas (ou dos serviços públicos). 
O método adotado por Mauss propõe hipóteses explicativas para esses fracassos. Essas hipóteses e referências convergentes permitiram a elaboração de uma teoria da economia solidária que se caracteriza por um novo paradigma da mudança social. Os referenciais dessa gênese da economia solidária na Europa visam, além disso, a aprofundar o diálogo com os teóricos da América do Sul.

\section{A experiência iugoslava: os limites de um modelo nacional de autogestão}

O século XX foi marcado pela tentativa de superar o capitalismo; a ditadura do proletariado, etapa fundamental na construção de uma sociedade comunista, devia tornar possíveis modificações de grande amplitude. Porém, no decorrer dos anos 1970, o esgotamento desse projeto, que vai culminar na derrocada dos países do Leste, torna-se manifesto. Todavia, a experiência da lugoslávia parece ser uma exceção, pois o não alinhamento do país parece permitir uma via original de conciliação entre o socialismo e a democracia, por meio de um sistema de administração das empresas qualificado de autogestão.

Em uma estadia de dois anos, tive a oportunidade de avaliar o teor desse sistema. O dossiê² que resulta disso conclui que a autogestão é mais um instrumento de comunicação externa do poder do que um vetor de democratização interna. As propensões autoritárias não poupam o país, como revela a introdução deste dossiê: retratação de uma pessoa entrevistada sobre as greves operárias, denúncias na imprensa oficial, vigilância

\footnotetext{
${ }^{2}$ Nesta nota e seguintes, estão indicadas as referências de minhas publicações: Autogestions, 1981, Les habits neufs du président Tito: critique, répression politique et luttes ouvrières en Yougoslavie, Toulouse, Privat, n. 6. de lecture Revue de sociologieves, ne voix.e la cobstruction d'x autres» économique alors qu'entent et délimitent le champ
} 
policial dos autores... Aliás, o mito da exceção iugoslava vai logo desmoronar, visto que os nacionalismos destroem tragicamente o federalismo instaurado por Tito, que não sobreviverá a ele.

No texto de 1924, Appréciation sociologique du bolchevisme, Mauss faz uma análise que explica não somente a falência do sistema soviético, mas também os obstáculos encontrados pela tentativa iugoslava de instaurar a autogestão por meio de um impulso estatal. Os comunistas, sociólogos ingênuos, acreditaram que a ordem soberana, a lei, pode criar, assim como o verbo de Deus, do nada, 'ex nihilo'. Obcecados com sonhos revolucionários, eles acreditaram refundar toda a sociedade humana (Mauss, 1997, p. 553). Mais precisamente, o estatismo revela o que Mauss chama de fetichismo político, isto é, a crença excessiva na capacidade transformadora da lei. Ora, ainda segundo ele, a lei revelou-se impotente quando não fundada nos costumes ou não moldada a práticas sociais suficientemente sólidas. Nesse sentido, a lei não cria, ela sanciona, ela pode realçar (Mauss, 1997, p. 550-552) práticas sociais, mas não pode inventar um mundo social.

A lucidez de Mauss permite relativizar as declarações correntes na época sobre o fracasso da autogestão. O excesso de democracia que levaria à ineficácia é uma explicação errônea dos limites do sistema. O problema não é a paralisia por excesso de consultas aos trabalhadores, nem o tempo perdido em intermináveis reuniões, como levava a crer uma literatura abundante. Trata-se mais de um déficit democrático devido a uma regulação burocrática sobre as diferentes instituições que supostamente permitiam a expressão coletiva.

Considerando o fracasso do controle político exercido sobre a economia, do qual a lugoslávia também fornece um exemplo, torna-se indispensável ou adaptar-se às realidades econômicas percebidas como leis naturais, ou conceber modalidades de democratização da economia que não passem pelo controle do Estado. É essa segunda hipótese que vai 
guiar as investigações para formas de empresas que buscam romper com a lógica capitalista.

\section{A economia social: os limites de uma abordagem pela empresa}

Na década de 1980, há uma recrudescência das cooperativas que reivindicam um funcionamento democrático porque repousam em uma mudança pelo direito de propriedade da empresa. Assim como as outras organizações da economia social (entidades mútuas, associações), elas garantem juridicamente uma igualdade formal entre os associados, de acordo com o princípio de uma pessoa, um voto.

Contra uma apreensão "bolchevique" da mudança social, é importante reabilitar essas experiências. Mais uma vez, a mensagem de Mauss é fundamental. Para ele, a verdadeira transformação só pode ser buscada a partir de mecanismos institucionais embasados em ações sociais; eles podem indicar os caminhos de uma reinserção da economia em normas democráticas, evitando um voluntarismo político que desemboque no autoritarismo. A reflexão sobre a conciliação entre igualdade e liberdade só pode progredir se considerar as reações que emanam da sociedade. Trata-se de apoiar-se em práticas para informar sobre sua existência, estudá-las e reforçá-las, ou seja, partir do movimento econômico real e não de um projeto calcado na realidade.

Todavia, as pesquisas efetuadas ressaltam que o status das organizações da economia social protege-as apenas parcialmente. As cooperativas, assim como qualquer outra organização, são submetidas a um isomorfismo institucional; com o tempo, acentua-se sua semelhança com as outras empresas. Passagem a um coopitalismo, concentração, inclusão em grupos não cooperativos, criação de filiais que os membros não con- 
trolam mais: todas essas tendências colocam evidentemente em questão a identidade das iniciativas envolvidas e suscitam questionamentos sobre as possibilidades de manter a originalidade da economia social em um contexto de intensa competição e de concentração rápida dos capitais.

Finalmente, diante da amplitude de sua banalização, impõe-se uma constatação: a economia social não conseguiu pesar nas escolhas da sociedade e promover de modo amplo a emancipação humana que ela encerra. Essa insuficiência não pode ser ignorada. Nesse caso, a incapacidade para engendrar uma mudança social pode ser correlacionada à representação da relação com a economia na teoria da economia social. Nesta última, com Fauquet (1965), ampliado por Vienney (1980; 1982), o modelo cooperativo tornou-se referência. A economia social é constituída por empresas a-capitalistas e o indicador de seu sucesso é o crescimento do volume de atividades mercantis, o que oculta uma incerteza sobre o funcionamento interno e as esferas não mercantis da economia. Esse quadro conceitual não só confunde igualdade formal nos estatutos e funcionamento democrático, como também sucesso econômico e inserção no mercado.

A economia social banalizou-se com o tempo, porque alimentou a ilusão de uma reforma que viria da simples existência de uma empresa diferente. Ela fracassou por esquecer o que Ihe confere sua originalidade, ou seja, a mobilização desta rocha das sociedades humanas (Mauss, 2012, p. 218-220) que é a dádiva. A seguridade social, a solicitude das entidades mútuas, da cooperação (ibid., p. 218-220) ultrapassam a dimensão organizacional, porque promovem uma moral de grupos onde se misturam o sentimento dos direitos do indivíduo e outros sentimentos mais puros (ibid., p. 218-220): de caridade, de serviço social, de solidariedade. Todavia, o risco da dádiva sem reciprocidade (Ranci, 1990) deve ser evitado, pois a caridade sempre magoa aquele que a aceita, e todo o esforço de nossa moral tende a suprimir o patrocínio inconsciente e injurioso do rico dadivoso (Mauss, 2012, p. 214). 
Para além da conceptualização da economia social, Mauss defende, portanto, um reconhecimento da especificidade do associativismo, isto é, do projeto constituído por ações coletivas executadas por cidadãos livres e iguais referindo-se a um bem comum. Esse associativismo não poderia ser reduzido a uma forma particular de empresa. A dádiva existe em todas as organizações, mas em algumas, como as empresas, a estrutura institucional quase não possibilita sua identificação, independentemente das propensões dos atores. O papel insubstituível do associativismo deve-se, pois, ao fato de que ele concretiza uma criação institucional fundada na solidariedade democrática e com uma dimensão econômica, contradizendo a assimilação dominante entre economia e mercado como a crença em uma onipotência do capitalismo.

Justamente quando as cooperativas perdem suas marcas distintivas por isomorfismo mercantil, surgem múltiplas iniciativas paralelas que recusam a mercantilização dos serviços da vida cotidiana, como a privatização dos bens comuns, ou que lutam contra as desigualdades sociais e por uma transição ecológica. Seus fomentadores consideram que a democratização da economia é indispensável para que o objetivo de emancipação possa ser mantido. O renascimento associativista manifesta-se principalmente por uma renovação de envolvimento solidário em atividades que revelam a introdução de comportamentos solidários nos atos econômicos mais correntes (criação de novos serviços e modos de troca, produção, comércio, consumo, poupança, etc.). Essas iniciativas lembram mais uma vez a atualidade de Mauss que, na conclusão do Ensaio sobre a Dádiva (2012), insiste na construção de instituições passíveis de preservar a existência concreta de dinâmicas solidárias efetivas, o que ele confirma em seus Ecrits politiques (1997). 


\section{A teoria da economia solidária}

Seu embasamento em uma resistência à sociedade de mercado torna inoperante o quadro conceitual da economia social. Para analisá-lo, o aporte de Mauss pode ser complementado com Polanyi (2011), que substitui a abordagem formal da economia ortodoxa por uma abordagem substancial e reconhece, além do mercado, princípios de integração econômica, de redistribuição, reciprocidade e administração doméstica. As práticas estudadas nos serviços de proximidade ${ }^{3}$ e em outros campos a partir dessa grade de leitura levam às hipóteses de impulso de reciprocidade e de hibridação em uma perspectiva de economia solidária, concebida como prolongamento e crítica à economia social. Retomando as propostas polanyianas, as relações entre economia e sociedade são assim consideradas do ponto de vista do vínculo entre pluralidade econômica e democracia.

Entretanto, a distância entre essa problemática e a corrente dominante da nova sociologia econômica, centrada nos mercados, suscitou muita incompreensão, como a acusação de que nega a diversidade desses mercados ou mesmo o laço social presente no laço mercantil. Evidentemente, a problemática da economia solidária não envolve tanta ingenuidade, apenas insiste na importância de não se reduzir a integração a seu aspecto de rede e de incluir a integração política, assim como o interesse pela distribuição entre os modos de alocação mercantil, não mercantil e não monetária, como ressalta Granovetter (2008, p. 39-40). Ela alerta para uma naturalização do mercado presente em trabalhos que tratam sobre serviços prestados a pessoas, e que confundem terceirização da esfera doméstica e mercantilização, e aponta a existência de inúmeras experiências em que o mercado não pode ser isolado, pois se acha articulado a

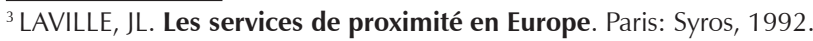


outras modalidades de organização da economia. Por exemplo, a sociologia dos mercados não dá conta dos serviços que incluem atividades de cuidado das pessoas - a sociologia econômica deve ser ampliada em um sentido pluralista ${ }^{4}$, de modo a incluir os outros princípios de integração (redistribuição, reciprocidade, administração doméstica).

A teorização agrega à pluralidade econômica a dimensão pública própria à economia solidária. Esta última diz respeito ao papel participativo e deliberativo do político, evidenciado por Arendt e Habermas, mas o amplia em três direções: pluralização, vínculo com o associativismo, articulação com as questões socioeconômicas.

A atividade comunicacional orientada para a justiça e a sinceridade (Habermas, 1987) não se reduz à troca de argumentos racionais, como mostraram inúmeros autores a partir de dados historiográficos (Calhoun, 1992), mas passa por atos que supõem tanto convicção e envolvimento por parte daqueles que os executam quanto esforços de persuasão e até mesmo de sedução. O conceito de espaço público pode ser sociologizado, caso o interesse se volte para o processo concreto pelo qual os cidadãos, cujas relações são regidas por princípios de igualdade e de liberdade, questionam a distância entre a afirmação democrática e a realidade. Assim, invertendo a perspectiva, um dos principais propulsores da ação coletiva é a negação de reconhecimento, que infringe os princípios democráticos. O espaço público, no sentido genérico, constitui simbolicamente a matriz da comunidade política, mas, como afirma Eley (1992), ele também está nas formas de expressão concretas através das quais se manifesta uma arena de significados contestados. Diferentes públicos buscam se fazer ouvir e entram em controvérsias. O espaço público está em contínua redefinição: uma parte dele sofre a pressão dos sistemas, en-

${ }^{4}$ LAVILLE, JL. Services aux personnes et sociologie économique pluraliste. Revue française de socio-économie, n. 2, La Découverte, p. 43-58, $2^{\text {nd }}$ semestre 2008. 
quanto espaços novos de formação da opinião e da vontade política são criados por múltiplas formas de agrupamento entre cidadãos. Essa reconfiguração permanente leva a se falar mais de espaço público policêntrico do que de espaço público único, como reconheceu o próprio Habermas (1992, p. 175).

Pode-se, então, passar da identificação de uma pluralidade de espaços públicos ao estudo das oposições internas. Muitos espaços públicos foram progressivamente dominados pelos meios de comunicação de massa e submetidos aos imperativos funcionais. A qualidade de vida democrática depende, assim, da constituição de espaços públicos autônomos, daí o vínculo com o associativismo, constituído de ações coletivas executadas por cidadãos livres e iguais que se referem a um bem comum. Para emancipar-se do paradigma da ação racional, é necessário mobilizar o conceito de associativismo, que permite conceber relações engendradas espontaneamente e livres de dominação de modo não contratualista (Habermas, 1989, p. 44). Por isso, a insistência de vários autores nas relações de associação e na

[P]osição eminente na sociedade civil de associações em torno das quais se podem cristalizar espaços públicos autônomos, que tenham "em comum uma atenção dada à associação voluntária e à vida associativa como principal meio para a definição dos envolvimentos públicos (Habermas, 1992, p. 186).

Segundo Benhabib (1992, p. 73-98), existiriam duas acepções em Arendt: um espaço público agonístico que privilegia o aparecimento com os outros, marcado pela grandeza moral e pelo heroísmo, um espaço público associativista que indica uma dimensão pública cada vez que seres humanos agem de comum acordo; se aceitarmos essa hipótese, a economia solidária diz respeito inegavelmente à versão associativista. 
Enfim, a separação praticada tanto por Arendt quanto por Habermas entre espaço público e esfera econômica não se mostra defensável. A divisão que Arendt estabelece entre o político de um lado e a economia e o social de outro impossibilita que se veja, como observa Fraser (1992, p. 109-142), o quanto a igualdade socioeconômica é uma precondição da paridade na participação pública. Em outras palavras, a distinção analítica entre as atividades humanas não pode ser convertida em uma dissociação empírica, a menos que se adote uma concepção ideológica herdada das instituições gregas (Salmon, 2011, p. 107; 118). Quanto a Habermas, mesmo concordando com sua afirmação de que as associações acolhem, condensam e repercutem, amplificando no espaço público político a ressonância que os problemas sociais encontram nas esferas da vida privada (Habermas, 1997, p. 394), pode-se criticar o fato de que esse papel seria apanágio de associações não estatais e não econômicas (ibid., p. 394). Essa alusão a uma categoria singular é pouco compatível com as constatações feitas em campo; a divisão entre associações deve ser substituída pelo estudo, em cada associação, de um lado, das tensões entre os contatos horizontais de interação que tangem à atividade comunicacional e intervêm na concepção dos problemas públicos e, de outro, de sua dimensão organizacional e integração em relações de poder.

\section{Uma renovação da abordagem da mudança social}

Mauss esboça os fundamentos teóricos de uma abordagem plural da economia, que pode ser complementada por Polanyi, e de uma abordagem plural da democracia, que pode dialogar com Arendt e Habermas, mas ele também principia uma reflexão sobre a mudança social, que não se satisfaz com a evocação ritual de um aniquilamento do sistema. 
Segundo ele, mais do que se entregar a um pós-capitalismo que oculta as dificuldades de uma transição, o melhor é partir de uma outra apreensão do que existe:

Não há sociedades exclusivamente capitalistas... Há apenas sociedades que têm um regime, ou sobretudo - o que é ainda mais complicado - sistemas de regime mais ou menos arbitrariamente definidos pela predominância de um ou outro desses sistemas ou dessas instituições ( Mauss, 2012).

Não há um modo único de organização da economia que seja a expressão de uma ordem natural, mas um conjunto de formas de produção e de repartição que coexistem. As representações individuais induzem ações e práticas sociais que as instituições normalizam pela política, delineando o quadro no qual as práticas podem se desenvolver e influindo sobre as representações. As instituições são mutáveis, porque são convenções sociais que experimentam e ao mesmo tempo delimitam o campo das possibilidades; seu estudo permite adquirir a consciência precisa dos fatos e a apreensão, senão a certeza, de suas leis e ajuda também a se distanciar desta "metafísica" de que são impregnadas as palavras em "ismo", como capitalismo. Afirmar a existência de uma sociedade capitalista equivale a admitir uma homogeneidade no interior do sistema econômico, ao passo que esse se compõe, na realidade, de mecanismos institucionais contraditórios, irredutíveis uns aos outros.

Para dar conta do estado das relações de força, é mais rigoroso falar de uma dominante capitalista, o que tem a vantagem de não ocultar a presença de outras formas e lógicas socioeconômicas.

Evidenciar os limites do estatismo leva não a um apagamento das instituições, mas a reconfigurações que podem corresponder à construção de instituições solidárias menos centralizadas, suscetíveis de sustentar os comportamentos individuais. Mauss insiste nas configurações institucionais que atestam a união entre o espírito da dádiva e a busca de igual- 
dade, características da solidariedade democrática. Passar a um projeto democrático de mudança social implica levantar a questão das instituições em condições de assegurar a pluralidade da economia para inscrevêla em um quadro democrático.

Nessa ótica, a necessidade de discussão sobre as interpretações dadas às experiências associativistas, indicada por Mauss, é hoje retomada com força por sociólogos como Sousa Santos (2000). Segundo este autor, integrando-as à análise, evita-se cair no cientificismo e retomar um estatismo desfigurado. Isso também significa fazer uma escolha epistemológica que ele julga imperiosa, a de Ciências Sociais abertas às manifestações, que não condenam as experiências por suas insuficiências, mas que são, ao contrário, atentas às suas potencialidades. De fato, elas dão novamente prioridade à ação cidadã em detrimento do determinismo econômico que dominou as abordagens da mudança social no século XX.

Jean-Louis Laville - Sociólogo. Coordenador Europeu do Instituto Karl Polanyi de Economia Política. Professor do Conservatoire National des Arts et Métiers, CNAM- Paris (França). $\gtrsim$ jean-louis.laville@lise.cnrs.fr

\section{Referências}

1. BENHABIB, S. Models of public space: Hannah Arendt, the liberal tradition, and Jürgen Habermas. In: CALHOUN, C. (ed.) Habermas and the Public Sphere. Cambridge MA et Londres: The MIT Press, 1992. p. 73-98.

2. CALHOUN, C. Habermas and the Public Sphere. Cambridge, MA et Londres: The MIT Press, 1992.

3. ELEY, G. Nations, publics and political cultures: Placing Habermas in the nineteenth century. In: CALHOUN, C. (ed.) Habermas and the Public Sphere. Cambridge, MA et Londres: The MIT Press, 1992. p. 289-338.

4. FRASER, N. Rethinking the public sphere: a contribution to the critique of actually existing democracy. In: CALHOUN, C. (ed.) Habermas and the Public Sphere. Cambridge, MA et Londres: The MIT Press, 1992. p. 109-142. 
5. FAUQUET, G. Le secteur coopératif. Paris: Institut des études coopératives, 1965.

6. HABERMAS, J. Théorie de I'agir communicationnel. Paris: Fayard, 1987. (Coll. L'espace du politique).

7. GRANOVETTER, M. Sociologie économique. Paris: Seuil, 2008. (Coll. Économie humaine).

8. HABERMAS, J. La souveraineté populaire comme procédure. Un concept normatif d'espace public, Lignes, n. 7, p. 29-58, 1989.

9. MAUSS, M. Ecrits politiques. Paris: Fayard, 1997.

10. MAUSS, M. L'essai sur le don. Paris: Presses Universitaires de France, 2012.

11. POLANYI, K. La subsistance de I'homme. Paris: Flammarion, 2011.

12. VIENNEY, C. Socioéconomie des organisations coopératives. Paris: CIEM, 2 vol., 1980-1982.

13. RANCI, C. Doni senza reciprocita. La persistenza dell'altruismo sociale nei sistemi complessi. Rassegna Italiana di Sociologia, Bologna, v. 31, n. 3, juil.-sept. 1990.

14. SALMON, A. Les nouveaux empires. Fin de la démocratie? Paris: CNRS Éditions, 2011.

Recebido em: 17/02/2014

Aceite final: 23/05/2014 